University of Nebraska - Lincoln

DigitalCommons@University of Nebraska - Lincoln

Faculty Publications from the Harold W. Manter Laboratory of Parasitology

$12-2003$

\title{
Molecular Phylogeny of Haematoloechus Looss, 1899 (Digenea: Plagiorchiidae), with Emphasis on North American Species
}

Daniel R. Brooks

University of Toronto,dnlbrooks@gmail.com

Virginia León-Règagnon

Universidad Nacional Autónoma de México

Follow this and additional works at: https://digitalcommons.unl.edu/parasitologyfacpubs

Part of the Parasitology Commons

Brooks, Daniel R. and León-Règagnon, Virginia, "Molecular Phylogeny of Haematoloechus Looss, 1899 (Digenea: Plagiorchiidae), with Emphasis on North American Species" (2003). Faculty Publications from the Harold W. Manter Laboratory of Parasitology. 257.

https://digitalcommons.unl.edu/parasitologyfacpubs/257

This Article is brought to you for free and open access by the Parasitology, Harold W. Manter Laboratory of at DigitalCommons@University of Nebraska - Lincoln. It has been accepted for inclusion in Faculty Publications from the Harold W. Manter Laboratory of Parasitology by an authorized administrator of DigitalCommons@University of Nebraska - Lincoln. 


\title{
MOLECULAR PHYLOGENY OF HAEMATOLOECHUS LOOSS, 1899 (DIGENEA: PLAGIORCHIIDAE), WITH EMPHASIS ON NORTH AMERICAN SPECIES
}

\author{
Virginia León-Règagnon and Daniel R. Brooks* \\ Laboratorio de Helmintología, Instituto de Biología, Universidad Nacional Autónoma de México, Apartado Postal 70-153, CP 04510 México, \\ D.F., México. e-mail: vleon@ibiologia.unam.mx
}

\begin{abstract}
Phylogenetic hypothesis of 23 populations corresponding to 18 species of the digenean Haematoloechus from America, Europe, and Africa, based on ribosomal DNA 28S partial sequences $(\sim 890 \mathrm{bp})$, is presented. Genetic divergence between the in-group and the out-groups ranged from 9.7 to $14.5 \%$ and within the in-group, from 0.9 to $12.2 \%$. Eight most parsimonious trees 569 steps long were obtained, with a consistency index of $72 \%$. Groups in the tree are not congruent with those in previous classification schemes of species in the genus, based on a small number of morphological characters. For this subset of Haematoloechus species, plesiomorphic hosts are species of Rana, with 2 colonizations to other amphibian groups. African species appear to have diverged after the separation of Gondwana and Laurasia. Therefore, South American species should appear as the closest relatives of African species when included in the analysis. The evidence presented suggests an ancestral wide distribution of North American representatives of the group, followed by successive contraction, amplification, and fragmentation of ranges and speciation events as a result of the intense volcanic activity in the central part of Mexico since the late Tertiary, the drying climate of western and central United States and northwestern Mexico from the early Eocene to the Pleistocene, and the glaciation during the Pleistocene.
\end{abstract}

Haematoloechus spp., the frog lung flukes, include some of the most common digeneans inhabiting frogs. More than 50 species have been described around the world, and their taxonomy has been highly controversial. Various authors have proposed different taxonomic schemes, grouping them in subgenera or proposing new genera to accommodate them (Odening, 1960; Skrjabin and Antipin, 1962; Yamaguti, 1971; Prudhoe and Bray, 1982). The cosmopolitan distribution of this genus and its host species (anurans and caudates) suggests a very ancient origin for the group. This was corroborated by a recent study of phylogenetic relationships among Holarctic species of Haematoloechus using ribosomal DNA (rDNA) sequences that evidenced the existence of clades with an origin predating the breakup of Laurasia (Snyder and Tkach, 2001). Great morphological divergence could be expected among species in the genus, considering their ancient origin and diversification; nevertheless, a similar general morphology and high intraspecific variation of some particular characters have led several authors to question the value of morphological traits in the recognition of Haematoloechus species or groups (Prokopic and Krivanek, 1974; Kennedy, 1980a, 1980b, 1981). All these features make the genus a highly desirable model system for assessing the utility of DNA sequences in solving taxonomic and phylogenetic problems (León-Règagnon et al., 1999, 2001; Snyder and Tkach, 2001; León-Règagnon and Paredes-Calderón, 2002).

In the present study, we update and expand the nucleotide sequence database for Haematoleochus species, using sequences of a variable region of the large subunit (LSU) of the rDNA to construct a phylogenetic hypothesis of species of Haematoloechus, evaluate morphological characters traditionally used to group species, and examine the biogeographic and coevolutionary patterns indicated by this subset of the genus.

\section{MATERIALS AND METHODS}

Collecting localities and hosts are detailed in Table I. Worms were identified in vivo; some samples were fixed in hot $4 \%$ formalin and

Received 17 February 2003; revised 25 April 2003; accepted 30 April 2003.

* Department of Zoology, University of Toronto, 25 Harbord Street, Toronto, Ontario, Canada M5S 3G5. preserved in $70 \%$ ethanol for morphological study and comparison. Samples for molecular work were preserved in absolute ethanol. Snyder and Tkach (2001) expressed some concern about the quality of the sequences published by León-Règagnon et al. (1999). Attending this concern, we resequenced some of those isolates, now using automated sequencing instead of manual sequencing, the method used to generate the original sequences (Table I). Standard phenol extraction methods were used to recover DNA from entire worms (single specimens). Laboratory protocols followed Hillis et al. (1996) and Palumbi (1996). Polymerase chain reaction (PCR) was used for amplifying the $5^{\prime}$ end of the $28 \mathrm{~S}$ rRNA gene $(\sim 890 \mathrm{bp})$, including the D1 variable region. Amplification and sequencing were performed using the primers $28 \mathrm{Sy}$ $5^{\prime}$ cta acc agg att cce tca gta acg gcg agt $3^{\prime}$ (forward) and 28Sz 5'aga ctc ctt ggt ceg tgt ttc aag ac 3' (reverse) (Hillis and Dixon, 1991). The amplification program consisted of $1 \mathrm{~min}$ at $94 \mathrm{C}$ followed by 35 cycles of $30 \mathrm{sec}$ at $92 \mathrm{C}, 30 \mathrm{sec}$ at $50 \mathrm{C}$, and $1 \mathrm{~min}$ at $72 \mathrm{C}$, followed by 4 min at $72 \mathrm{C}$ for final elongation. PCR products were sequenced directly on an ABI Prism 310 automated DNA sequencer. Sequences are available in GenBank with the accession numbers listed in Table I. Additional sequences for 10 Haematoloechus spp. isolates and for the 3 outgroups were obtained from previous publications (Tkach et al., 2000; Snyder and Tkach, 2001; León-Règagnon and Paredes-Calderón, 2002). Sequences were aligned visually using the computer program Bioedit (Hall, 1999). All analyses were conducted using PAUP 4.0b10 (Swofford, 2002). An uncorrected distance matrix was obtained for the pairs of examined sequences. Phylogenetic signal in the data set was estimated using the g1 statistic (Hillis and Huelsenbeck, 1992) with 10,000 randomly generated trees. An unweighted maximum parsimony (MP) analysis using a branch and bound search was performed considering character states as unordered and gaps as missing data or as a fifth base. A nonparametric bootstrap (BTP) with 1,000 replicates was run to evaluate the robustness of the clades.

\section{RESULTS}

\section{Sequences}

The fragment of the ribosomal gene $28 \mathrm{~S}$ for the 26 examined sequences varied from 852 to $884 \mathrm{bp}$, resulting in an alignment of 889 positions. Aligned sequences are available at TreeBASE with the accession number M1435. Genetic divergence between the in-group and the out-groups ranged from 9.7 to $14.5 \%$ and within the in-group, from 0.9 to $12.2 \%$. In some cases, the rDNA sequences from species of the in-group are less similar to each other (H. micrurus vs. H. breviplexus, $12.2 \%)$ than those from species from the in-group and the out-group $(H$. exoterorchis vs. Haplometra cylindracea, 9.7\%). 


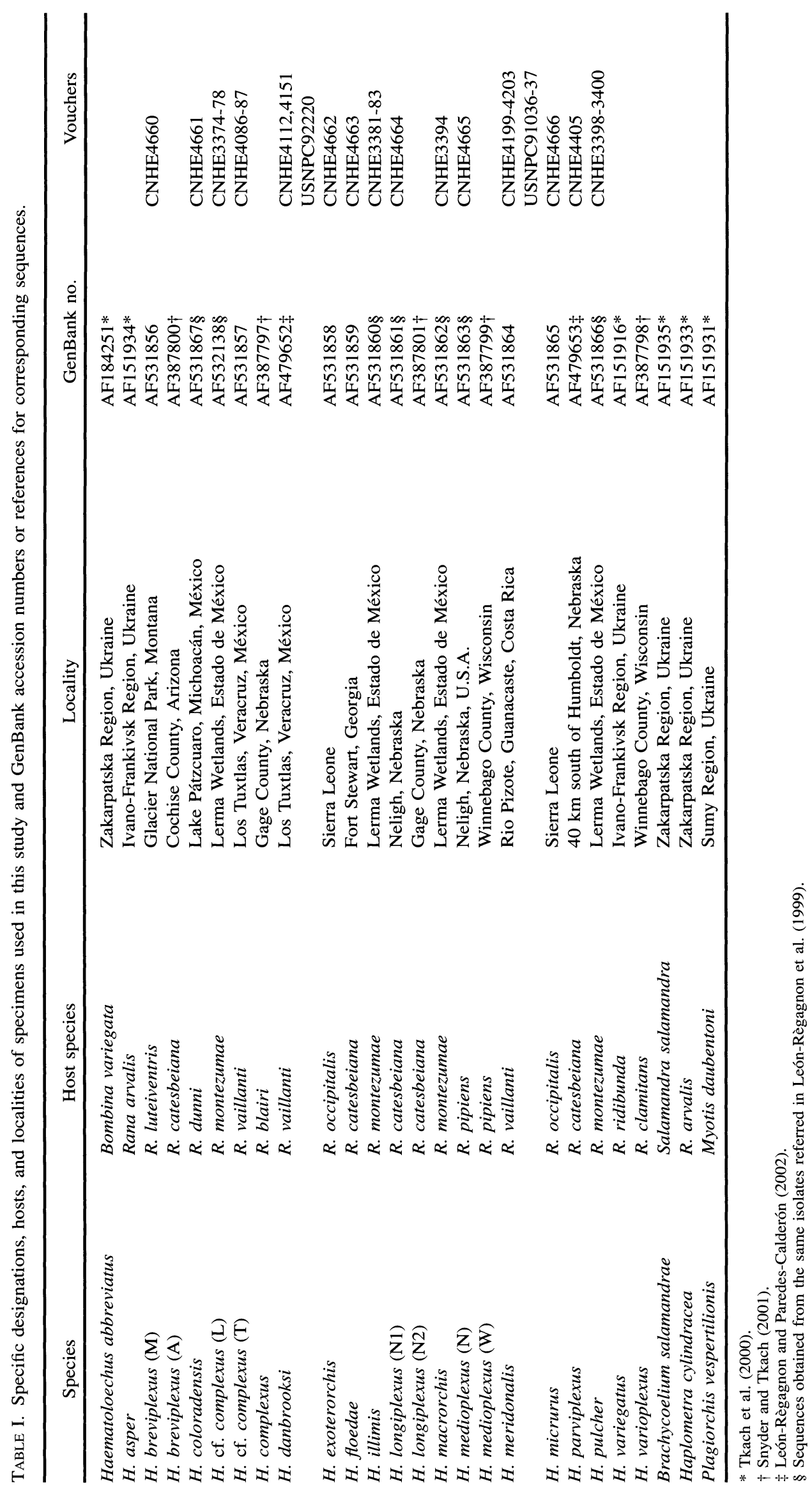




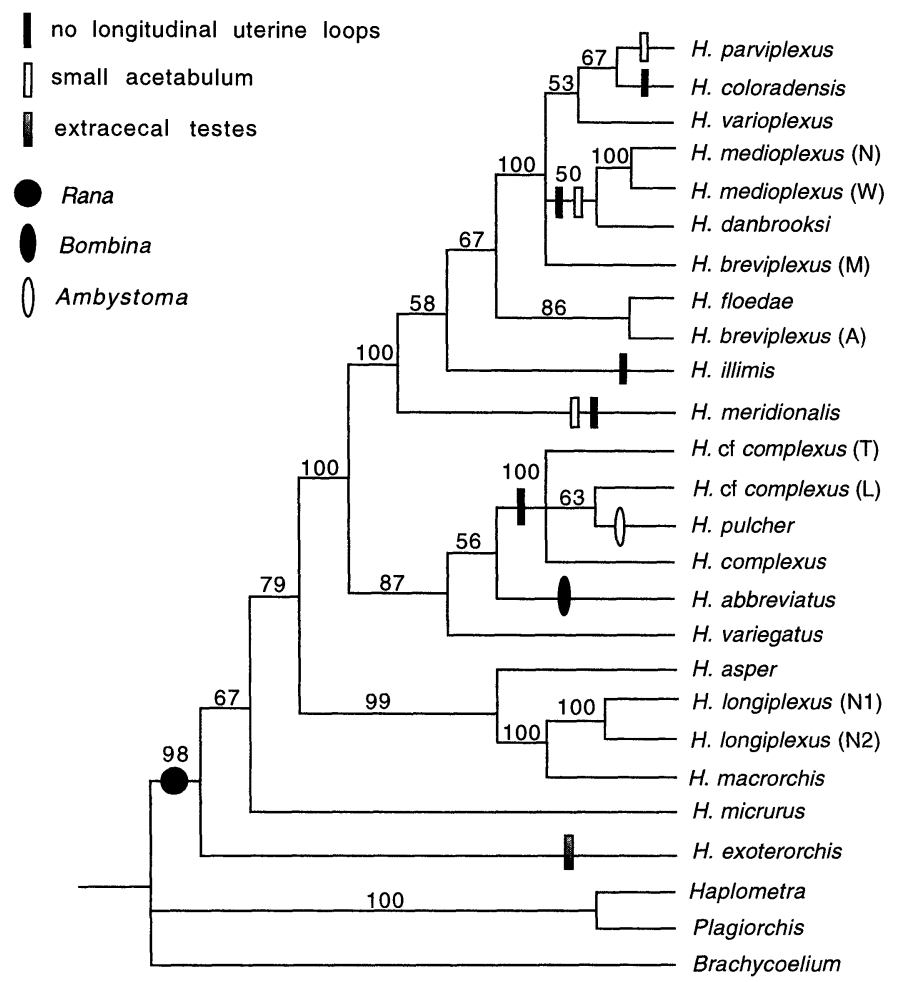

FIGURE 1. Strict consensus of the 8 most parsimonious trees for the fragment of the rDNA $28 \mathrm{~S}$ gene examined in this study, showing morphological traits and preferential hosts mapped on the tree. Names correspond to those assigned in Table I. Numbers above branches indicate BTP support.

\section{Phylogenetic analysis}

The data set presented a significant phylogenetic signal (g1 $=-0.646, P>0.01$; mean \pm SD tree length $1,171.44 \pm 42.06$, range 958-1,260). The MP analysis performed with the 26 taxa provided 262 (308 considering gaps as a fifth base) variable characters, 173 (181) of which were parsimoniously informative. Four (8) equally parsimonious trees were obtained, 486 (569) steps long, with a consistency index of $0.69(0.72)$ and a retention index of 0.82 .

The strict consensus of the 4 most parsimonious trees obtained considering gaps as missing data (Fig. 1) shows Haematoloechus exoterorchis as the sister species to the rest of the in-group. In the next node, $H$. micrurus appears as the basal species for 2 major clades. One of them $($ BTP $=99)$ includes $H$. asper as the sister species of $H$. longiplexus and $H$. macrorchis. The second clade $(\mathrm{BTP}=100)$ comprises 2 groups; 1 of them includes 2 European species $(H$. abbreviatus and $H$. variegatus) basal to a polytomy comprising specimens assigned to the North American H. complexus group. The second group includes only American species; the Central American species $H$. meridionalis is basal, followed by 1 Mexican species $(H$. illimis) with a low BTP support (58). The next clade is also weakly supported, showing $H$. floedae $+H$. breviplexus (of Snyder and Tkach, 2001) as the sister taxa of a polytomy formed by North American species. Within this clade, H. danbrooksi appears as sister species of $H$. medioplexus, and $H$. varioplexus is the sister species of $H$. parviplexus $+H$. coloradensis. Poor resolution and low BTP support were obtained in this part of the tree. The consensus tree of the 8 most parsimonious trees obtained considering gaps as a fifth base is identical, except for the North American species clade, which is less resolved.

\section{DISCUSSION}

\section{Sequences divergence}

Snyder and Tkach (2001) suggested that the amount of variation in sequences of rDNA of several species of Haematoloechus from Mexico and the United States observed by LeónRègagnon et al. (1999) was the result of errors in the methodology used by those authors, and they recommended caution in the use of those data by others. Following their suggestion, we compared LSU sequences from León-Règagnon et al. (1999) with those obtained in this study. León-Règagnon et al. (1999) used manual sequencing in their study; the differences found with the sequences we obtained in this study from the same samples, but using automated sequencing, apparently are the result of misinterpretation of autoradiographs. Snyder and Tkach (2001) expressed their concern about the great variation shown between 2 sequences of $H$. longiplexus from different localities in the study of León-Règagnon et al. (1999), compared with the small variation found by these authors in different populations of 2 European species. León-Règagnon et al. (1999) considered 2 populations from Nebraska and Central Mexico to belong to $H$. longiplexus. Further research on sequences of specimens from distant populations of $\mathrm{H}$. floedae have shown them to be identical or to differ only in 2 sites. These observations, together with the evidence presented by Snyder and Tkach (2001) about the low divergence among populations of $H$. longiplexus, suggest that the synonymy of $H$. macrorchis with $H$. longiplexus suggested by León-Règagnon et al. (1999) was premature and that they are actually valid species that are morphologically very similar.

In the LSU fragment that we studied herein, we found no genetic variation between 2 close populations of $H$. longiplexus (both in the state of Nebraska) and little genetic divergence between 2 populations of $H$. medioplexus from Nebraska and Wisconsin $(0.3 \%)$. The sequence assigned to $H$. breviplexus from Arizona by Snyder and Tkach (2001) differs by $0.2 \%$ from our sequence of $H$. floedae from Georgia and by $3.5 \%$ from the sequence of $H$. breviplexus from Montana.

Haematoloechus breviplexus, originally described from Ontario, Canada, is morphologically similar to $H$. floedae, originally described from Texas. Various authors have considered $H$. floedae as a junior synonym of $H$. breviplexus (Odening, 1960; Kennedy, 1981). We examined the voucher specimen identified as $H$. breviplexus by Snyder and Tkach (2001) (USNPC 91507) and corroborated that it actually belongs to $H$. floedae. It differs from $H$. breviplexus in the shape of the testes, the more anterior uterine longitudinal loops in H. floedae, and the distribution of the vitelline follicles, which are smaller and more numerous in $H$. floedae, reaching different levels on each side of the body. According to the morphological and molecular data presented herein, $H$. floedae is a valid species, and the sequence presented by Snyder and Tkach (2001) for $H$. breviplexus probably came from a misidentified specimen of $H$. floedae. Although the known geographic distribution of $H$. floedae is in the south- 
eastern United States, wide dispersion of the definitive host due to human activities could have widened its range.

In our study, the amount of genetic divergence is more similar among sequences of different populations previously assigned to $H$. complexus than among sequences from specimens assigned to different species (i.e., $H$. coloradensis and $H$. parviplexus), suggesting that Mexican isolates of this species could represent independent lineages. Nevertheless, with the information available to date, species limits are difficult to establish in this morphologically conservative group. Genetic variation among populations of the entire geographical range of the complex of species needs to be carefully explored.

The amount of divergence between some pairs of species of the in-group is strikingly high $(H$. breviplexus vs. $H$. micrurus, $12.2 \%$ ), surpassing that observed between some species of the in-group and the out-group (H. exoterorchis and Haplometra cylindracea, $9.7 \%$ ). In a phylogenetic study of the Plagiorchiata (Tkach et al., 2001), Haplometra cylindracea and European species of Haematoloechus appear in distantly related clades within the group. Nevertheless, those clades appear with a very low BTP support in Tkach et al.'s (2001) study, and it is possible that Haematoloechus and Haplometra are more closely related than they appear if additional evidence is evaluated. In any case, $H$. exoterorchis has been considered to be an independent genus, Metahaematoloechus, based on the position of the testes (Yamaguti, 1970), and the present study gives support to that proposal.

\section{Morphological traits}

Analysis of the phylogenetic history of Haematoloechus spp. is hindered by the absence of any phylogenetic analyses based on a large suite of morphological traits. Currently, a small number of morphological characters are used to classify Haematoloechus spp., and they do not support the groups in our phylogenetic hypothesis (Fig. 1). The arrangement of the uterine loops has been 1 of the most important taxonomic characters for differentiation of species and classification of the group. Several authors have considered that species without extracecal longitudinal uterine loops constitute a different genus, Ostiolum (Pratt, 1930; Odening, 1960; Skrjabin and Antipin, 1962; Yamaguti, 1971; Prudhoe and Bray, 1982). According to our analysis, Haematoloechus spp. is paraphyletic if species without extracecal longitudinal uterine loops are grouped in a different genus (Fig. 1). This assertion is in agreement with previous studies in which species without longitudinal uterine loops do not appear as closest relatives (León-Règagnon et al., 1999; Snyder and Tkach, 2001). Size of the acetabulum relative to oral sucker has also been an important taxonomical feature in the genus. In our analysis, species with acetabula less than $50 \%$ the size of the oral sucker are all included in the clade of North American species, although they do not appear as a monophyletic group within this clade (Fig. 1). BTP support of this part of the tree is low. Only by the inclusion of more taxa, including those without acetabula (proposed to form an independent genus, Neohaematoloechus Odening, 1960), and the use of additional molecular markers will we be able to test the validity of this character as indicative of evolutionary lineages. Haematoloechus exoterorchis was suggested to constitute a different genus, Metahaematoloechus, characterized by having extracecal testes (Yamaguti, 1971; Prudhoe and Bray, 1982). Our hypothesis is consistent with that classification scheme (although with a low BTP support). Representatives of Skrjabinoeces (European species with vitelline follicles limited to the anterior part of the body) need to be included in the analysis to test the value of the distribution of vitelline follicles for the classification of the group. Arrangement of the uterine loops and size of the acetabulum are apparently useful to distinguish species of the genus but do not represent the phylogenetic affinities within the group.

\section{Host and geographical affinities}

Mapping preferential hosts on the tree (Fig. 1) indicates that plesiomorphic hosts are species of Rana and colonization of members of Bombina (H. abbreviatus) or ambystomatids (if $H$. pulcher is a valid species) may have led to speciation events through host switching. Within Rana, no obvious coevolutionary pattern can be distinguished because several different lineages of frogs (Hillis and Davies, 1986) are infected by species of the same group of worms. The $H$. complexus group apparently has been limited to leopard frogs, but, again, it is necessary to perform further studies using more informative DNA regions for this taxonomic level to determine whether coevolutionary phenomena have occurred between these groups. Haematoloechus species are morphologically conservative, and it is possible that only with the use of molecular markers will we be able to understand whether we are dealing with 1 , or several, different species parasitizing leopard frogs in Mexico.

Our hypothesis is also consistent with previous analysis suggesting an origin of the group predating the breakup of Pangea (Snyder and Tkach, 2001). North American, European, and African representatives of Haematoloechus do not form monophyletic groups (Fig. 2). According to our study, African species diverged early in the diversification of the group, after the breakup of Gondwana and Laurasia, during the late Triassic. To obtain a fuller picture of the evolution of this group, we need to include South American, Asian, and Australian species in the analysis. For example, Cordero and Vogelsang (1939) suggested a Nearctic origin for the South American species described during that period, assigning a North American ancestral species to each one of them. Their scenario implies many colonization events of North American species and subsequent speciation events in South America. If the hypothesis based on the small subset of species used in this and previous molecular studies is correct, we predict that South American species of Haematoloechus would appear as the closest relatives of African species when included in the analysis.

According to our observations on the Mexican and Central American species of Haematoloechus, the southernmost areas in the distribution of the majority of the Nearctic species that extend their distribution to Mexico (H. coloradensis, H. complexus) appear to be the Mesa Central, the southern part of Veracruz State, along the Atlantic coast, and the lowlands of Guerrero on the Pacific coast of Mexico (León-Règagnon et al., 1999; Pérez-Ponce de León et al., 2000; this study). In the Mesa Central and in the lowlands of both coasts, there appears to be a mixture of Nearctic species and endemics of southern Mexico and Central America (H. coloradensis, H. complexus, H. floedae, H. macrorchis, H. illimis, $H$. danbrooksi, $H$. pulcher, $H$. 


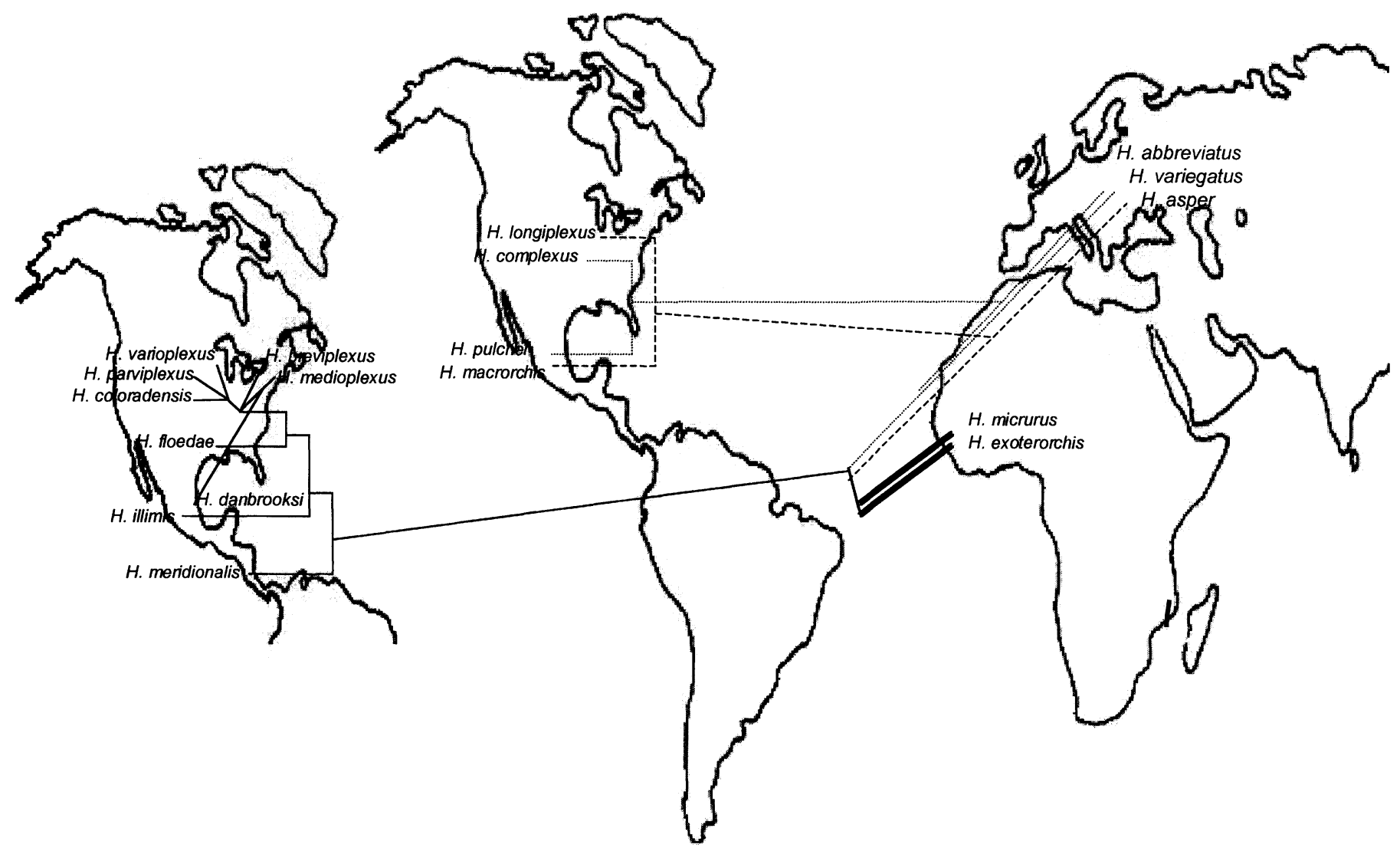

FiguRE 2. Strict consensus of the 8 most parsimonious trees superimposed on a map showing geographical distribution of species of Haematoloechus included in this study.

meridionalis). In our phylogenetic hypothesis, species from Middle America appear scattered in the tree, together with typically Nearctic species, in 1 case being basal to North American species (H. meridionalis and $H$. illimis) (Fig. 2). This evidence suggests a wide ancestral distribution of North American representatives of the group, followed by successive contraction, amplification, and fragmentation of ranges and speciation events. These activities were the result of intense volcanic activity in the central part of Mexico since the late Tertiary, the drying climate of western and central United States and northwestern Mexico from the early Eocene to the Pleistocene, and the glaciating event during the Pleistocene (Rosen, 1978; Ferrusquía-Villafranca, 1998). Regions that maintained a stable climate during these events include the southeastern United States, the Gulf of Mexico coast, the Yucatan Peninsula, and parts of extreme western North America. It has been recognized that several groups of organisms show a geographical distribution more or less congruent with these areas as a result of the retraction of their original range during those periods of geologic and climatic change (Rosen, 1978; Byerly, 1991). In our analysis of Haematoloechus spp., we recognize some taxa that follow this geographical pattern, i.e., H. floedae, which is distributed in the southeastern United States and is found in the Yucatan Peninsula. Haematoloechus longiplexus is distributed in the eastern United States; its sister species, H. macrorchis, is found in eastern Central Mexico. Haematoloechus coloradensis is found from the western United States to Central Mexico and the Pacific coast. Additional inventory in Central America may produce more species of Haematoloechus, helping us to complete this part of the story. In addition, we believe that the use of sequence data from mitochondrial genes may give us information at a lower taxonomic level, i.e., the actual species and geographic ranges of members of the $H$. complexus group.

\section{ACKNOWLEDGMENTS}

We are deeply grateful to Robert Bourgat, Anna Schotthoefer, David Green, and Anindo Choudhury for donation of specimens; Rosario Mata, Laura Paredes, Elizabeth Martínez, Agustín Jiménez, Rogelio Rosas, Ulises Razo, Edmundo Pérez, and Alejandro Zaldivar for their help in field collections; and Edmundo Pérez, Alejandro Zaldivar, and Adrián Nieto for identification of hosts. Special thanks are due to Laura Márquez Valdelamar (Molecular Biology Laboratory, Instituto de Biología, Universidad Nacional Autónoma de México [IBUNAM]) for her help in the sequencing of samples and Gerardo Pérez-Ponce de León for his revision of an earlier version of the manuscript. This study was funded by Consejo National de Ciencia y Tecnologia (CONACYT) project J27985-N to V.L.-R., National Science Foundation (NSF) grant DEB0102303 to Jonathan Campbell and V.L.-R., and an operating grant form the Natural Sciences and Engineering Research Council (NSERC) of Canada to D.R.B.

\section{LITERATURE CITED}

ByerLy, G. R. 1991. Igneous activity. In The Gulf of Mexico basin: The geology of North America, vol. J., A. Salvador (ed.). Geological Society of America, Boulder, Colorado, p. 91-108.

Cordero, E. H., AND E. G. Vogelsang. 1939. Nuevos Tremátodos, I. Dos Especies del Género Pneumonoeces Looss, del pulmón de Rana palmipes Spix, de Venezuela. Revista de Medicina Veterinaria y Parasitología 1: 173-179. 
Ferrusquía-Villafranca, I. 1998. Geología de México: Una sinopsis. In Diversidad biológica de México: Orígenes y distribución, T. P. Ramamoorthy, R. Bye, A. Lot, and J. Fa (eds.). Universidad Nacional Autónoma de México, Mexico, Mexico, p. 3-108.

HALL, T. A. 1999. Bioedit: A user-friendly biological sequence alignment editor and analysis program for Windows 95/98/NT. Nucleic Acids Symposium Series 41: 95-98.

HILLIS, D. M., AND S. K. DAVIES. 1986. Evolution of ribosomal DNA: Fifty million years of recorded history in the frog genus Rana. Evolution 40: $1275-1288$.

, AND T. M. DiXon. 1991. Ribosomal DNA: Molecular evolution and phylogenetic inference. The Quarterly Review of Biology 66: 411-453.

, AND J. P. HuelSENBECK. 1992. Signal, noise and reliability in molecular phylogenetic analyses. Journal of Heredity 83: 189-195. -, B. K. Mable, AND C. Moritz. 1996. Nucleic acids IV: Sequencing and cloning. In Molecular systematics, D. M. Hillis, C. Moritz, and B. K. Mable (eds.). Sinauer Associates, Sunderland, Massachusetts, p. 321-383.

KENNEDY, M. J. 1980a. Host-induced variations in Haematoloechus buttensis (Trematoda: Haematoloechidae). Canadian Journal of Zoology 58: 427-442.

-1980b. Geographical variation in some representatives of Haematoloechus, Looss, 1899 (Trematoda: Haematoloechidae) from Canada and the United States. Canadian Journal of Zoology 58: $1151-1167$.

- 1981. A revision of species of the genus Haematoloechus Looss, 1899 (Trematoda: Haematoloechidae) from Canada and the United States. Canadian Journal of Zoology 59: 1836-1846.

León-Règagnon, V., D. R. Brooks, and G. Pérez-Ponce de León. 1999. Differentiation of Mexican species of Haematoloechus Loss, 1989 (Digenea: Plagiorchiformes): Molecular and morphological evidence. Journal of Parasitology 85: 935-946.

- - AND D. A. Zelmer. 2001. Morphological and molecular description of Haematoloechus meridionalis n. sp. (Digenea: Plagiorchioidea: Haematoloechidae) from Rana vaillanti Brocchi of Guanacaste, Costa Rica. Journal of Parasitology 87: 1423-1427. - AND E. L. PARedes-CAlderón. 2002. Haematoloechus danbrooksi n. sp. (Digenea: Plagiorchioidea), from Rana vaillanti of
Los Tuxtlas, Veracruz, Mexico. Journal of Parasitology 88: 12151221 .

OdENING, K. 1960. Plagiorchiidae III. (Haematoloechinae) und Omphalometrinae. In Das Tierreich. Eine Zusammenstellung und Kennzeichnung der rezenten Tierformen, R. Mertens and W. Hennig (eds.). Walter de Gruyter \& Co., Berlin, Germany, p. 1-75.

PALUMBI, S. R. 1996. Nucleic acids II: The polymerase chain reaction. In Molecular systematics, D. M. Hillis, C. Moritz, and B. K. Mable (eds.). Sinauer Associates, Sunderland, Massachusetts, p. 205-247.

Pérez-Ponce de León, G., V. León-Règagnon, L. García-Prieto, U. RaZo-Mendivil, AND A. SÁNCHEZ-Alvarez. 2000. Digenean fauna of amphibians from Central Mexico: Nearctic and Neotropical influences. Comparative Parasitology 67: 92-104.

PRATT, H. S. 1930. Description of four distomes. In Mark Anniversary Volume, G. H. Parker (ed.). Henry Holt Publishers, New York, New York, p. 25-38.

Prokopic, J., AND K. KRIVANeK. 1974. Trematodes of the genus Haematoloechus Looss, and their variability. Helminthologia 15: 779 802.

Prudhoe, S., AND R. A. BRay. 1982. Platyhelminth parasites of the Amphibia. Oxford University Press, Oxford, U.K., 217 p.

Rosen, D. E. 1978. Vicariant patterns and historical explanation in biogeography. Systematic Zoology 27: 159-188.

SkrJabin, K. I., AND D. N. ANTIPIN. 1962. The superfamily Plagiorchioidea Dollfus, 1930. In Trematodes of animals and man, vol 20, K. I. Skrjabin (ed.). Akademy Nauk, CCCR, Moscow, Russia, p. 47-163. [In Russian.]

SNYDER, S., AND V. TKACH. 2001. Phylogenetic and biogeographical relationships among some holarctic frog lung flukes (Digenea: Haematoloechidae). Journal of Parasitology 87: 1433-1440.

SwOFFORD, D. L. 2002. PAUP*: Phylogenetic analysis using parsimony (*and other methods), version 4. Sinauer Associates, Sunderland, Massachusetts.

TKaCh, V., J. Pawlowski, and J. Mariaux. 2000. Phylogenetic analysis of the suborder Plagiorchiata (Platyhelminthes, Digenea) based on partial lsrDNA sequences. International Journal for Parasitology 30: $83-93$.

YAMAGUTI, S. 1971. Synopsis of digenetic trematodes of vertebrates Keigaku Publishing Co., Tokyo, Japan, 1074 p. 